\title{
Blinding Lights (The Weeknd): pautas formales y contenido de marca en el videoclip del año de MTV
}

\section{Blinding Lights (The Weeknd): formal techniques and branded content in MTV's Video of the Year}

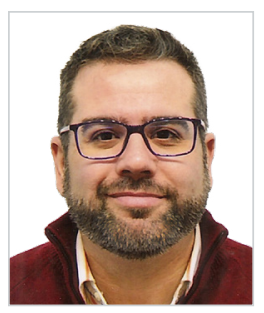

José Patricio Pérez-Rufí. Profesor Contratado Doctor del Departamento de Comunicación Audiovisual y Publicidad de la Facultad de Ciencias de la Comunicación de la Universidad de Málaga desde 2009. Es Doctor por la Universidad de Sevilla, licenciado en Comunicación Audiovisual y licenciado en Periodismo por la Universidad de Sevilla. Imparte en la Universidad de Málaga las asignaturas de Estructura del Mercado Audiovisual y Diseño Gráfico. Ha publicado diversas monografías en editoriales como Síntesis, Quiasmo, Eumed o T\&B, además de un amplio número de artículos en revistas académicas de Comunicación. Es miembro del Equipo de Investigación COMMUNICAV Procesos de creación, producción y postproducción audiovisual y multimedia (SEJ585).

Universidad de Málaga, España

patricioperez@uma.es

ORCID: 0000-0002-7084-3279

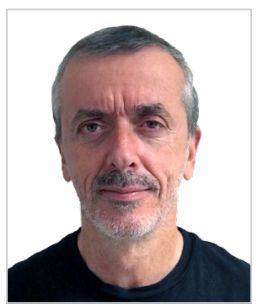

Antonio Castro-Higueras. Doctor en Comunicación experto en industrias culturales y creativas. Es Profesor Contratado Doctor de la Facultad de Ciencias de la Comunicación de la Universidad de Málaga. Ha impartido formación de grado y posgrado en la Universidad Internacional de la Rioja (UNIR), la Universidad Internacional Isabel I y ha sido tutor del Grado en Diseño y Creación Digitales de la Universitat Oberta de Catalunya (UOC). En el ámbito profesional ha sido Subdirector Técnico Nacional de la red de televisiones Localia TV, Director Técnico de la productora del Grupo Prisa, Plural Entertainment, y productor de programas divulgativos para TVE2, entre otras actividades relacionadas con la televisión.

Universidad de Málaga, España

acastro@uma.es

ORCID: 0000-0001-7406-5550

Recibido: 17/12/2020 - Aceptado: 04/03/2021 - En edición: 01/04/2021 - Publicado: 14/06/2021

Resumen:

Esta investigación tiene por objetivo principal el análisis textual del videoclip Blinding Lights de The Weeknd, premio a Vídeo del año 2020 en los galardones MTVVideo Music Awards. Destacamos este vídeo como modelo representativo de las prácticas del formato en el contexto contemporáneo. Partimos de la hipótesis de que MTV premia un vídeo que prolonga prácticas formales y narrativas clásicas y modélicas, incluso convencionales, a pesar de la apertura del formato a la experimentación formal. Pretendemos a través
Received: 17/12/2020 - Accepted: 04/03/2021 - Early access: 01/04/2021 - Published: 14/06/2021

Abstract:

This research aims to provide a textual analysis of the Blinding Lights music video by The Weeknd, winner of Video of the Year 2020 at the MTV Video Music Awards. We have chosen this video clip as a representative model of this format in the contemporary context. Our initial hypothesis is that MTV awarded this music video because it prolongs classical and exemplary formal and narrative techniques, even conventional ones, despite the format's openness to formal experimentation. We intend through textual

Cómo citar este artículo:

Pérez-Rufí, J. P. y Castro-Higueras, A. (2021). Blinding Lights (The Weeknd): pautas formales y contenido de marca en el videoclip del año de MTV. Doxa Comunicación, 32, pp. 187-205.

https://doi.org/10.31921/doxacom.n32a9 
del análisis textual descubrir las claves de su articulación formal, con un propósito divulgativo. La aplicación de un análisis textual sobre una sola obra audiovisual supone una aplicación habitual en los estudios sobre el videoclip. El análisis textual permite identificar aquí prácticas frecuentes en el formato: variedad de encuadres con un sentido funcional, abundantes movimientos de cámara, falta de continuidad entre planos, una débil narratividad o la ordenación circular de acontecimientos, entre otros. Además, Blinding Lights es paradigmático de la producción de vídeos musicales por su evidente finalidad comercial, como parte de una estrategia de branded content para la marca automovilística Mercedes-Benz.

Palabras clave:

Videoclip; televisión; contenido de marca; análisis textual; industria discográfica.

\section{Introducción}

En 1987 el grupo británico Depeche Mode editó el álbum Music For The Masses con un título irónico, conscientes de que la música electrónica que producían no contaba con la aceptación masiva del rock y del pop. Paradójicamente, se convirtió en un éxito sin precedentes en la historia del grupo, al punto de llevarles a reproducir las dinámicas de la escenificación pública de las estrellas del rock, llenando estadios en sus presentaciones en directo en Estados Unidos. A través de esta anécdota queremos introducir una cuestión compleja: la conversión de productos culturales aparentemente de vanguardia y experimentación formal en productos de consumo popular y masivo. En el espacio en que confluyen diversos formatos artísticos con objetivos comerciales, el videoclip, objeto de nuestro estudio, supone un eslabón entre la pura creación artística y la abierta comercialidad de la publicidad.

Pese a las dificultades que implica el intento de definición del videoclip (Sedeño-Valdellós, 2002; Viñuela, 2008; Vernallis, 2013), habitualmente ha sido entendido como un formato audiovisual con una naturaleza formal ligada a la experimentación, la exploración como recurso de expresión cultural y la aplicación de novedosas tecnologías de filmación y edición, pero también se ha solido aludir a su carácter funcional como herramienta al servicio de un objetivo comercial. La experimentación audiovisual se subordina así a la función comercial, al punto de que dicha comercialidad llega a condicionar su lenguaje.

Desde esta naturaleza dual, Selva-Ruiz (2014: 101) define el vídeo musical como un "formato audiovisual empleado por el sector fonográfico como herramienta de comunicación comercial, que se basa en la adición de imágenes a una canción preexistente". En un sentido muy similar, Rodríguez-López (2016: 15) lo entiende como "un producto audiovisual y promocional de la industria discográfica que toma influencias directas del lenguaje cinematográfico, publicitario y de las vanguardias artísticas". 
Un acercamiento a su lugar en la cultura y en la sociedad puede llevar a que identifiquemos el videoclip como "una mercancía cultural privilegiada dentro de las industrias culturales dominantes para reproducir la ideología y la cultura hegemónica entre la juventud del sistema-mundo" (Illescas-Martínez (2017: 87). Con respecto a su contenido propiamente, Guarinos-Galán y Sedeño-Valdellós (2020: 121) identifican "una tendencia en el videoclip contemporáneo a emplear asuntos sociales actuales en sus narrativas, con las que plantean problemáticas contextualizadas en un presente cambiante". De esta forma, el vídeo musical va más allá de su naturaleza formal experimental y de su función comercial para añadir un carácter testimonial de los valores vigentes en su momento de producción, como de hecho ocurre con todas las manifestaciones culturales.

En cuanto a su lenguaje, podríamos afirmar que la repetición de prácticas lleva a una modelización del discurso y consecuentemente a la articulación de una cierta gramática del videoclip, flexible y sujeta a cambios de forma constante, pero con cierta coherencia.

La reiteración en el uso de recursos puede llevar a la parodia también en el vídeo musical: la parodia nace de la imitación de fórmulas previas, lo que requiere el análisis previo y la réplica de sus aspectos más evidentes. Creemos oportuno el comentario de un vídeo paródico distribuido por YouTube en relación directa con nuestro objeto de estudio. La pieza cómica titulada If Educational Videos Were Filmed Like Music Videos, publicada en el canal de Tom Scott (2018) el 15 de octubre de 2018, con dirección de Sammy Paul, compila una serie de prácticas frecuentes en el vídeo musical, como resultado de un análisis textual, y con un objetivo humorístico. Entre las prácticas comentadas en el vídeo destacamos las siguientes: el plano inicial es confuso y de aspecto irreal fruto del uso del ralentí, mantenido en el resto del clip, la edición ofrece planos de muy breve duración sin continuidad entre ellos, se introducen marcas comerciales (product placement), se aceleran algunos planos para destacar ciertas acciones, pese a lo cual hay sincronización labial con la parte vocal de la canción, se activa el sonido diegético (ambiente) y concluye con el plano inicial para transmitir una impresión de circularidad narrativa. Si todo un formato audiovisual puede parodiarse es porque puede analizarse, categorizarse, modelizarse y, finalmente, replicarse.

Esta investigación tiene por objetivo principal el análisis textual de un videoclip que podría considerarse representativo de las prácticas actuales y que responde a tendencias frecuentes y consolidadas, al punto de que mantiene las opciones formales modelizadas en las réplicas y las parodias del formato. La hipótesis propuesta por este estudio es que a pesar de la variedad de posibilidades que el formato del vídeo musical permite, la pieza más destacada de 2020 para MTV prolonga prácticas en cuestiones narrativas y en decisiones de tipo formal (de realización, edición y postproducción) que mantienen un modelo clásico de videoclip, al punto de poder llegar a ser convencional o modélico. La vanguardia formal con la que surge el vídeo musical no solo se modeliza hasta llegar a ser común, sino que es premiada por la cadena insignia del formato, MTV. Así, MTV, que en sus orígenes ofrecía un modelo de programación disruptiva, programa y premia piezas conservadoras en lo formal, cuarenta años después de su nacimiento.

MTV es un canal de televisión (o más bien una franquicia de canales) perteneciente al grupo mediático ViacomCBS, que entrega los premios MTVVideo Music Awards (MTVVMA) desde 1984. De forma paralela, existen otros galardones de la cadena de televisión dedicados a las diferentes franquicias internacionales de la marca y a su audiencia en Europa, Asia, 
Latinoamérica, Japón, Rusia o Australia. MTV exporta en todo el grupo de canales, además de su modelo programático y sus contenidos, los eventos mediáticos relacionados con la marca.

En el año 2020 MTV mantuvo su voluntad de celebrar la ceremonia y de premiar los vídeos musicales votados por su audiencia a partir de una propuesta de candidaturas realizada por la cadena. La expansión del coronavirus Covid-19 y la pandemia universal en que derivó ha significado un revulsivo en la industria discográfica y en la propia producción de clips, pero no ha detenido la industria y se ha mantenido la creación, distribución y comercialización de contenidos por parte de las compañías. Como consecuencia de la adaptación de las condiciones de producción de vídeos, MTV introdujo en 2020 dos categorías de galardones apropiadas a las circunstancias de producción del videoclip y de la industria discográfica, en general: Mejor presentación de cuarentena (Best Quarantine Performance) y Mejor vídeo desde casa (Best Music Video From Home). Proponemos para un futuro trabajo el análisis de los clips nominados a ambos galardones como muestra del formato creado bajo unas condiciones muy particulares. Nuestro interés aquí es el premiado como Vídeo del año, por cuanto podría ser representativo del conjunto de la producción del formato en circunstancias normales.

En un contexto en el que plataformas VoD como YouTube se han convertido en el medio prioritario de distribución del vídeo musical, MTV mantiene su relación con el formato, incluso si prácticamente ha desaparecido de su programación, a través de los galardones anuales (en Estados Unidos y en sus diferentes ediciones internacionales). A falta de una academia que, como en otros galardones televisivos o cinematográficos, sea la autoridad a la hora de premiar el vídeo musical, MTV sigue siendo la institución de referencia que destaca unas producciones y les otorga el prestigio y el reconocimiento público de unos premios.

Este trabajo aplica una metodología de análisis textual sobre una muestra formada por un único videoclip. El vídeo musical seleccionado es además un caso de éxito tanto en ventas como en reproducciones: Blinding Lights de The Weeknd fue el mejor videoclip del año 2020 según los espectadores de MTV. El vídeo fue premiado en certámenes como UK Music Video Awards 2020, MTV Video Music Awards Japan 2020, LOS40 Music Awards 2020 o Variety's Hitmakers 2020, y recibió nominaciones en otros concursos y festivales dedicados al formato.

Tenemos como objetivo secundario una intención didáctica. El análisis textual de un videoclip representativo de un momento de producción concreto debe poder ofrecer unos resultados y unas conclusiones capaces de convertir dicha pieza en una práctica paradigmática, además premiada por la audiencia, de donde podría derivarse una posterior aplicación práctica por parte de docentes y estudiantes en materia de comunicación audiovisual. Entendemos la aplicación docente de los resultados de una investigación como un objetivo legítimo en un trabajo académico. Consideramos así que el análisis textual de un clip concreto puede conseguir los objetivos que se han propuesto.

Como segundo objetivo secundario, planteamos un estudio de caso de Blinding Lights como muestra de branded content, de tal forma que el análisis textual aplicado sobre el vídeo musical integra también criterios formales relacionados con la representación y el impacto de la marca en la pieza audiovisual. Podemos entender el concepto de branded content (o contenido de marca) como una fusión de publicidad y entretenimiento en un producto cultural destinado a ser distribuido como contenido de entretenimiento al tiempo que se integra en una estrategia de marketing de una marca (Horrigan, 2009). Estos formatos publicitarios propondrían "formatos dialógicos no invasivos, que favorezcan 
la participación del receptor y la generación de experiencias que recordarán y relacionarán con emociones positivas" (Costa-Sánchez, 2015: 85).

El estudio del videoclip y de la MTV como canal de televisión fundacional y como precursor del formato cuenta con una amplia tradición, destacando los trabajos de Jones (2005), Gow (1996), Selva-Ruiz (2010), Tannenbaum y Marks (2011) o Bonde Korsgaard (2017). Estos trabajos han llegado en algún caso a hacer videoclip y MTV sinónimos, destacando las particularidades de su formato estrella como vehículo de identidad del canal televisivo; los cambios en la programación de MTV y la multiplicación de canales especializados en géneros concretos con la marca MTV ya son introducidos en los estudios sobre MTV más recientes. Los estudios formales como el que aquí proponemos cuentan con menos literatura académica. Subrayamos, en todo caso, las valiosas aportaciones de Sedeño (2002), Vernallis (2013), Selva-Ruiz (2014), Rodríguez-López (2014) o Vernallis, Rogers y Perrott (2019). Las principales contribuciones de estas investigaciones en la disciplina han sido las metodologías de análisis textual y la idea de que tales metodologías pueden y deben ser adaptadas al objeto de análisis y a los objetivos de la investigación, hecho que invita al desarrollo de investigaciones exploratorias sobre el formato.

Más insólitos resultan los trabajos que han puesto en relación al videoclip con el branded content, destacando en todo caso Sánchez-Olmos (2018). Por el contrario, los trabajos que han analizado el product placement en el vídeo musical son mucho más abundantes, teniendo principalmente como objetivos la identificación de marcas, tipos de productos o el lugar del emplazamiento en muestras objetivas basadas en listados de éxitos en YouTube o Billboard (Pérez-Rufí, Navarrete-Cardero y Gómez-Pérez, 2014; Sánchez Olmos, Segarra Saavedra e Hidalgo Marí, 2019; Sedeño y Schubert, 2020).

\section{Metodología}

Tomamos una muestra intencional para el análisis de un vídeo, aquel premiado como Vídeo del año a partir de las votaciones de la audiencia dentro de las nominaciones realizadas por MTV. Basándose en el estudio de los vídeos premiados en los certámenes entre 1984 y 2016, Rodríguez-López y Pérez-Rufí (2017) sostienen que una muestra de tipo probabilística conforme a criterios reflexivos y razonados justificaría la elección. MTV se convierte aquí en el referente "institucional" que acredita la popularidad y la calidad de las piezas que selecciona para las nominaciones a sus premios. Podríamos añadir que una muestra de nominados y premiados representaría, por una parte, la aceptación popular de unas piezas que han recibido un feedback positivo por parte de la audiencia; por otra, supone la apuesta de la industria musical y televisiva por unos contenidos con los que se siente identificada, otorgándoles distinción y valor (Pérez-Rufí, 2011).

Consideramos que el Vídeo del año 2020 para la audiencia de MTV articula un lenguaje formal convencional del videoclip. Este vídeo fue Blinding Lights de Abel Tesfaye, intérprete y músico canadiense solista que actúa bajo el nombre de The Weeknd. A lo largo de su carrera Tesfaye, o The Weeknd, ha ganado tres Premios Grammy, dos American Music Awards, nueve Billboard Music Awards, nueve Juno Awards, además de haber sido nominado a un Óscar por la canción Earn It del filme Fifty Shades of Grey (Sam Taylor-Wood, 2015) y de haber recibido varias nominaciones en diversas ediciones de los premios MTV. Blinding Lights recibió en la gala de los MTV VMA 2020 el premio a Vídeo del año y otro 
más como Mejor vídeo R\&B, de entre siete nominaciones. La canción fue escrita y producida por el músico junto a Max Martin y Oscar Holter, con créditos adicionales de Belly y Jason Quenneville. El vídeo fue dirigido por Anton Tammi y fue filmado en Las Vegas y en Los Ángeles durante cuatro jornadas de rodaje (Blanco, 2020), siendo finalmente publicado en YouTube el 21 de enero de 2020. La canción y el propio músico formaron parte de una campaña de Mercedes-Benz desarrollada a partir del 29 de noviembre de 2019, tras la firma del acuerdo entre las partes en febrero de 2019 (Billboard, 2019), campaña que después conectó con la narrativa y el estilo desarrollados en el vídeo musical.

La aplicación de un análisis textual sobre una sola obra audiovisual supone una práctica frecuente en los estudios fílmicos y televisivos, pero también en el videoclip. Muestra de este modelo de investigación son los trabajos de Vernallis (2013) acerca de clips de Beyoncé y Lady Gaga, Tarín Cañadas (2012) en una pieza de Radiohead, o Roig y Cornelio (2015) sobre las producciones alrededor de un tema de Pharrell Williams.

Proponemos una metodología de análisis basada en el análisis textual del videoclip, acorde a los objetivos de esta investigación. A través del análisis textual del discurso audiovisual aplicado al vídeo musical intentamos identificar su articulación formal, el empleo de recursos narrativos y discursivos y la configuración de la puesta en escena, además de interpretar su significado. Las metodologías de análisis textual podrían reconocerse como herramientas integradas dentro del análisis de contenido, aquel que según López Noguero (2002: 174) pretende "descubrir los componentes básicos de un fenómeno determinado extrayéndolos de un contenido dado a través de un proceso que se caracteriza por el intento de rigor de medición".

Nuestro análisis se dividirá en cuatro apartados, partiendo de una adaptación de la metodología propuesta por Pérez-Rufí y Jódar-Marín (2019) a los objetivos de la investigación. El primer apartado del análisis es la fase previa, donde anotamos los datos que ubican la pieza en su contexto de producción: videoclip e intérprete, autoría, dirección del vídeo musical, autoría de la canción, discográfica del single (según la web Discogs.com), personal implicado en la producción del clip (según aparece publicado en YouTube), enlace en YouTube, fecha de publicación en dicha plataforma, género musical (según Discogs.com), BPM (velocidad del tema) y escala (Discogs.com), duración del videoclip y duración del single. Atendemos en esta fase previa también a la información publicada acerca de la campaña de branded placement en que se integra la pieza.

La segunda fase atendería al contenido del videoclip: partiremos, en primer lugar, de una breve descripción del vídeo para, posteriormente, categorizarlo según la tipología propuesta por Sedeño-Valdellós (2002): el videoclip descriptivo, como representación de la interpretación del tema musical por el grupo o cantante (performance) o como experimentación estética entorno a diversos códigos visuales (conceptual); el videoclip narrativo, que desarrolla un relato con los elementos que conforman la narratividad; y el videoclip mixto, que combina elementos del clip descriptivo (performance o conceptual) con el narrativo. En relación directa con esta clasificación, evaluamos la narratividad de la pieza a partir de la activación o no de sus componentes: presencia de acontecimientos, personajes y transformación de la situación (Casetti y Di Chio, 1991). A continuación, exponemos las temáticas abordadas en la pieza. En este caso, la interpretación es la herramienta necesaria para categorizar el contenido en un sentido u otro. Evaluamos también el impacto que tiene 
el contenido desarrollado en el vídeo en la representación de la marca y en los valores que transmite a ésta como parte de la estrategia de branded content.

La tercera fase propone el análisis formal audiovisual de la muestra, con categorías que atienden a cuestiones relacionadas con la realización, la edición y la postproducción. Con respecto a la realización observamos las siguientes categorías: encuadres más frecuentes según la escala europea de planos (PG, plano general; PE, plano entero; PA, plano americano; PM, plano medio; PP, primer plano; PD, plano detalle); presencia y función de los movimientos de cámara (zoom, travelling, travelling digital), angulación de cámara (normal, picado, contrapicado); activación del sonido diegético (sonido ambiente). Dentro del análisis de la edición de la pieza atendemos a los aspectos relativos a la percepción subjetiva de ritmo (a partir de la conjugación de la duración de los planos, los movimientos de cámara, el movimiento interno dentro del encuadre y la tensión del contenido del plano); velocidad del plano (normal, ralentí, acelerado); tipo de transición entre planos (corte, encadenado, fundido, barrido, cortinilla). En cuanto a la postproducción, damos cuenta de la presencia de infografía y efectos visuales digitales (VFX) y describimos el uso del grafismo y de los recursos textuales (diegéticos, en el caso de que formen parte de la puesta en escena filmada, o extradiegéticos, si no formasen parte del espacio registrado y se integrasen a través de la edición). En cuanto al análisis de la estrategia de branded content en el videoclip desde la óptica formal, atendemos también al tipo de planos, movimientos de cámara y al modo en que marca y producto aparecen en el discurso, así como las cuestiones relacionadas con la edición de ambos motivos en el vídeo.

La cuarta fase de esta metodología propone el análisis de la puesta en escena. El análisis de la puesta en escena en el audiovisual describe la forma y los componentes del encuadre. Incluye elementos del lenguaje audiovisual en parte coincidentes con los precedentes del teatro: composición del plano (que simplificamos observando la aplicación de la regla de tercios o la composición simétrica), escenografía (artificial o natural, con intenciones realistas o dramáticas), iluminación (con intención funcional o no, realista o dramática), caracterización (vestuario y maquillaje, evaluados como realistas o no, apropiados a la actuación de los personajes o no) y actuación (es decir, si el acting de los caracteres es adecuado a la acción desarrollada en el relato o no, con las posibles intenciones realistas o no). También en este apartado atendemos brevemente a la integración de la marca Mercedes dentro de la puesta en escena.

No abordamos el análisis formal de una muestra mayor de piezas con la que comparar los resultados del videoclip analizado, por cuanto consideramos que iría más allá de los objetivos de esta investigación. Acerca de las pautas formales más repetidas sobre el videoclip, Selva (2014: 482) afirma que "en la mayoría de los casos, cada videoclip se adapta a las convenciones del género en el que se inscribe". Si bien dichas pautas convienen ser seguidas, es necesaria "una experimentación y una reinvención constantes que están justificadas por razones de estricta eficacia” (Selva, 2014: 506). Selva rechaza, igualmente, la idea de que los vídeos más originales huyen de las convenciones del formato, "ya que es probable que, precisamente, estos videoclips logren cumplir su cometido con una mayor eficacia gracias a dicha dosis de creatividad" (Selva, 2014: 506). 


\section{Resultados}

\subsection{Fase previa del análisis}

Tabla 1. Fase previa del análisis

\begin{tabular}{|c|c|c|c|}
\hline Videoclip & \multicolumn{3}{|l|}{ Blinding Lights } \\
\hline Intérprete & \multicolumn{3}{|l|}{ The Weeknd } \\
\hline Dirección & \multicolumn{3}{|l|}{ Anton Tammi } \\
\hline Autoría canción & \multicolumn{3}{|c|}{ Abel Tesfaye, Ahmad Balshe, Jason Quenneville, Max Martin, Oscar Holter } \\
\hline Discográfica & \multicolumn{3}{|l|}{ Republic Records, Universal } \\
\hline Autoría & \multicolumn{3}{|c|}{$\begin{array}{l}\text { Actriz: Miki Hamano; Compañía productora: Somesuch; Productor ejecutivo: Saskia Whinney; Productora: Sa- } \\
\text { rah Park; Director de fotografía: Oliver Millar; Director de segunda unidad: Devin "Daddy" Karringten; Stea- } \\
\text { dicam: Niels Lindelien; Jefe del equipo técnico: Nizar Najm; Jefe de producción: Marlow Nunez; Diseño de } \\
\text { producción: Adam William Wilson; Primer asistente de dirección: Kenneth Taylor; Editor: Janne Vartia \& Tim } \\
\text { Montana; Supervisor de postproducción: Alec Ernest; VFX: Mathematic; Colorista: Nicke Jacobsson; Diseño de } \\
\text { sonido: Akseli Soini; 3D: Oscar Böckerman; Diseño de títulos de crédito: Aleksi Tammi. }\end{array}$} \\
\hline Enlace & https://youtu.be/4NRXx6U8ABQ & Publicación & $21 / 01 / 20$ \\
\hline Género & Pop (Synthwave, New Wave) & BPM/clave & 171/ D Major \\
\hline Duración clip & $4: 22$ & Duración single & $3: 21$ \\
\hline
\end{tabular}

Fuentes: YouTube, Discogs, Billboard. Elaboración propia

La canción Blinding Lights de The Weeknd fue publicada el 29 de noviembre de 2019 por Republic Records (filial de Universal Music), como segundo single del álbum After Hours, editado el 20 de marzo de 2020. Con producción de Max Martin, célebre productor sueco con 23 temas que alcanzaron el número 1 en la lista Billboard estadounidense, el single fue editado el mismo día en que se difundía la campaña de Mercedez-Benz para promocionar su modelo de coche eléctrico Mercedes-Benz EQC 400 4MATIC. El tema fue la banda sonora de los diferentes spots de la campaña, donde destaca el anuncio Enjoy electric. With the all-new EQC x The Weeknd "Blinding Lights", en el que el propio músico conduce el vehículo para dar paso a escenas que representan diferentes momentos históricos y localizaciones en las que la intervención de automóviles de la marca juega un papel central. La evolución del automóvil a lo largo de su historia concluye con el intérprete conduciendo su último modelo mientras canta la canción.

El videoclip del tema, editado el 20 de enero de 2020, contaba con la popularidad que le dio la campaña, lo que, más allá de su valor artístico y su atractivo para la audiencia, explica su éxito en charts y en reproducciones de YouTube. El videoclip también muestra al intérprete conduciendo un Mercedes, en concreto el descapotable Mercedes-AMG GT (Blanco, 2020), creando así una continuidad con la campaña publicitaria previa. La introducción de la marca en el discurso es muy sutil, lo que lleva a una buena integración del mensaje publicitario sin que podamos interpretar una estra- 
tegia de product placement forzado. El uso de marcas procedentes del lujo, entre las que se encuentra las automovilísticas, supone una práctica frecuente en el videoclip, como demuestran Sedeño-Valdellós y Schubert (2020).

Antes que de product placement, en este caso deberíamos hablar de branded content. Señalan Del Pino-Romero y Castelló-Martínez (2015: 111) que, a diferencia del product placement, el producto no solo se integra en el contenido "sino que las marcas crean su propio contenido para compartirlo con los usuarios". No tenemos apenas indicios para afirmar que el tema musical fue compuesto para la campaña publicitaria, pero sí que sus piezas audiovisuales (spots y videoclip) responden a la voluntad de ponerse al servicio de la marca.

La estrategia fue exitosa tanto para el músico y su discográfica como para la marca automovilística, con el éxito de la campaña (al menos en reproducciones en YouTube) y de la canción reforzado mutuamente. Si ya de por sí el videoclip cuenta con una naturaleza comercial como pieza promocional para la venta de una canción o la creación de una identidad para un artista, en casos como el analizado, en el que queda clara su concepción dentro de una estrategia de branded content, los límites entre spot y videoclip se diluyen.

Apuntemos como aspectos extradiscursivos del videoclip que fue dirigido por Anton Tammi, realizador con nueve clips, según la base de datos Imvdb.com (2020), para la productora Somesuch \& Co. El vídeo fue rodado en las calles de Las Vegas (en Fremont Street, en concreto) y en Los Ángeles y continúa la trama iniciada por el vídeo del single previo, Heartless, con el mismo equipo de producción, que después continúa con el vídeo del tercer single, In Your Eyes.

\subsection{Análisis de contenido}

Tabla 2. Análisis de contenido de la muestra

\begin{tabular}{|c|c|c|c|}
\hline Descripción & Tipo & $\begin{array}{l}\text { Narrativi- } \\
\quad \text { dad }\end{array}$ & Temas \\
\hline $\begin{array}{l}\text { El cantante deambula por las calles desiertas de una gran ciudad por la noche, } \\
\text { algunas de ellas en Las Vegas, mientras baila y corre fuera de sí, pareciendo } \\
\text { feliz. Conduce veloz, acude a un local de música en vivo donde una cantante } \\
\text { lo hace volar hacia ella, recibe una paliza y sigue bailando. }\end{array}$ & Narrativo & Sí, débil & $\begin{array}{l}\text { Embriaguez. Violen- } \\
\text { cia. Lujo. } \\
\text { Situaciones de riesgo. }\end{array}$ \\
\hline
\end{tabular}

Fuente: elaboración propia

El vídeo musical muestra a The Weeknd vagando por un escenario nocturno, urbano y desierto, que reconocemos en algunas escenas como Las Vegas, donde ríe, baila y corre al tiempo que conduce un automóvil a toda velocidad por unas calles desiertas. Como continuación del anterior vídeo, Heartless, sabemos que el intérprete ha bebido una gran cantidad de alcohol y está drogado después de haber lamido un sapo con resultados alucinógenos, lo que puede explicar su comportamiento delirante y despreocupado pese a ser agredido por los encargados de seguridad de un local en el que actúa una cantante de rasgos asiáticos que -literalmente- lo hace volar hasta el escenario. La conducción temeraria del personaje por una ciudad desierta y los bailes en plena autovía o en un túnel atravesado por una carretera crean tensión por la situación de riesgo a la que se expone. 
Más allá de la continuidad con el anterior clip, algunos planos remiten al filme Fear and Loathing in Las Vegas (Terry Giliam, 1998), donde el personaje interpretado por Johnny Depp sufría alucinaciones en la ciudad del juego tras consumir drogas. Otros referentes más o menos obvios son filmes desarrollados en Las Vegas como Casino (Martin Scorsese, 1995), Ocean's Eleven (Steven Soderbergh, 2001) o The Hangover (Todd Phillips, 2009), además de videoclips como I Still Haven't Found What I'm Looking For de U2 (Barry Devlin, 1987) o Viva Las Vegas de ZZ Top (Warner Bros Records, 1992).

La letra de la canción tiene una temática amorosa: el intérprete expresa a otra persona cómo la echa de menos. Alude a dos asuntos expuestos en el clip: salir a conducir a toda velocidad (So I hit the road in overdrive, baby) y los espacios urbanos desiertos que encuentra a su paso (I look around and Sin City's cold and empty; Oh, the city's cold and empty). La mención en la letra a una acción como "activarse con un toque" (You can turn me on with just a touch, baby) es interpretada literalmente en el spot de la campaña de Mercedes, pista que podría invitarnos a pensar que la creación de la propia canción ya formaba parte del branded content de la marca.

Con respecto al tipo de videoclip, podríamos categorizarlo como narrativo, dado que desarrolla el relato de las acciones y las transformaciones que implican a un personaje. Sin embargo, activa una débil narratividad, por cuanto podría hilarse la evolución de los acontecimientos -desordenados- representados en el vídeo que experimenta el personaje, aunque la causalidad que entrelaza las escenas resulta antes de una interpretación de las acciones expuestas que de un relato narrativo fuerte. El clip recoge así diferentes momentos en el recorrido nocturno de un personaje que deambula sin un objetivo definido, sin una clara línea narrativa. Considerando tanto el clip precedente (Heartless) como el que le seguiría (In Your Eyes), es posible una interpretación más completa de la cadena de acontecimientos que vive el personaje y de los géneros cinematográficos a los que remite, pero por sí solo Blinding Lights resulta insuficiente para una interpretación clara de su narratividad. La repetición de escenas muy similares y el desorden de la secuencia de los acontecimientos representados dan una sensación de circularidad al conjunto.

Los temas abordados tienen relación con las adicciones, el estado de embriaguez o de intoxicación por consumo de drogas, el exceso, las situaciones de riesgo, el lujo, la violencia y la atracción sexual. Se crea una enorme tensión entre los contextos de riesgo para su salud y de violencia y la actitud descuidada y entusiasmada del protagonista. Esta tensión es potenciada por el contraste entre planos con encuadres muy amplios que subrayan la soledad del personaje y su temeridad en plena carretera.

Podríamos entender con respecto al contenido una representación supuestamente autocrítica o paródica del intérprete, lejos de roles moralmente positivos. The Weeknd pone en riesgo su vida, drogado, en Las Vegas, componiendo un personaje excesivo y negativo como modelo social pero carismático, tanto como lo han sido villanos cinematográficos como Joker en el film homónimo de Todd Phillips (2019) o como mucho antes Alex en A Clockwork Orange (Stanley Kubrick, 1971).

La representación de este rol de dudosa moralidad se hace dentro de un discurso de ficción, incluso si el cantante parece interpretarse a sí mismo. Esta ambigua composición del personaje resulta, con todo, coherente con la identidad oscura y con las tramas inquietantes que Abel Tesfaye ha protagonizado en los vídeos musicales de su carrera artística previa.

Apuntemos con respecto a la integración de la marca Mercedes y del vehículo dentro de la narración y del discurso, que se hace con naturalidad y sin resultar forzada. El producto tiene un rol activo dentro de la historia, los planos en 
los que se aprecia la marca requieren un visionado atento y hay una coherencia entre la historia y los componentes de la puesta en escena, entre los que se incluye el vehículo. No estamos ante un caso de product placement en el que debe hacerse evidente que los personajes "muestran" a cámara el producto en plano detalle sin que tenga relación con el relato desarrollado.

La conducción del personaje es peligrosa, lo que se suma a su dudosa moralidad; podríamos sospechar que el coche ha sido robado por el simple gesto de colocarse un guante antes de entrar en el mismo, aunque tampoco es un hecho que se confirme. Sin embargo, el vehículo y la marca no se cargan de valores negativos, más bien al contrario: el personaje contempla fascinado el vehículo, incluso sus detalles, y aunque conduce en estado de embriaguez, también se muestra eufórico en la expresión de la más absoluta y anárquica libertad que conlleva la conducción acelerada sin un destino concreto. La satisfacción que le provoca el manejo del vehículo en su errático recorrido por los espacios urbanos nocturnos desiertos es habitual en los spots televisivos de automóviles: se trata de un coche veloz, eficaz, urbano, glamuroso, elegante y digno del estatus social de una persona de alto nivel adquisitivo, como el propio personaje parece representar pese a su rol antagonista. El peligro que entraña la conducción temeraria del intérprete puede llegar incluso a reforzar la idea de seguridad del vehículo: a pesar de todo, The Weeknd no sufre un accidente de tráfico, tal vez por tratarse de un Mercedes. Tenemos, por lo tanto, una muestra de branded content que integra muy bien las virtudes del producto sin resultar forzado, evitando además una idealización irreal de tal producto, esta vez al ser utilizado por un personaje oscuro de comportamiento reprobable.

\subsection{Análisis formal (realización, edición, postproducción)}

Tabla 3. Análisis formal

\begin{tabular}{|c|c|}
\hline \multicolumn{2}{|l|}{ Realización } \\
\hline Tipos de planos & Planos muy variados, destacan planos cortos y PGs \\
\hline Angulaciones & Variada \\
\hline Movimientos de cámara & Travelling, zoom, cámara en mano, zoom digital \\
\hline Sonido diegético & Sí \\
\hline \multicolumn{2}{|l|}{ Edición } \\
\hline Impresión de ritmo & Rápido \\
\hline Velocidad del plano & Normal. Algunos planos en ralentí y acelerados \\
\hline Transiciones entre planos & Al corte. Barridos \\
\hline \multicolumn{2}{|l|}{ Postproducción } \\
\hline VFX & Sí \\
\hline Grafismo/texto & Texto extradiegético \\
\hline
\end{tabular}

Fuente: elaboración propia 
La atención a los aspectos formales en las cuestiones relativas a la realización reconoce la variedad de recursos en todos los sentidos y su funcionalidad clásica. Así, con respecto a la planificación y los tipos de encuadres, consideramos que estos son muy variados y responden a intencionalidades convencionales en la gramática audiovisual: los Planos Generales ubican al personaje o la acción en un contexto, permitiendo la descripción de los escenarios, que aquí son fundamentales para entender la soledad del personaje y el contraste de su actuación temeraria con espacios de civilización. Los Planos Medios captan la interacción del personaje con su entorno y los Primeros Planos ponen el foco en la emoción y en las reacciones del personaje. Los Planos Detalle del personaje o de partes del automóvil terminan por componer un mosaico de encuadres cortos cuidados e incluso preciosistas, a pesar del carácter urbano y nocturno, por no decir "feísta", del conjunto.

Frente a la habitual colocación de la cámara en angulaciones normales, el clip alterna constantemente ésta con angulaciones contrapicadas y picadas, lo que combinado con la gran variedad de encuadres presentes y su edición acelerada termina por reforzar la impresión de fragmentación del discurso. Los movimientos de cámara son constantes y diferentes, alternándose travellings rodados con grúa o soportes móviles con otros tomados cámara en mano, acentuando la inestabilidad del personaje y la impresión de ritmo. Los planos en los que el soporte de cámara es portado por el propio intérprete subraya sus movimientos y la visión subjetiva (y alucinada) de aquel.

Se edita con sonido ambiente (sonido diegético) el ruido del automóvil y del espacio urbano, lo que aporta un efecto de realismo y de velocidad en la arriesgada conducción del protagonista. El protagonismo del Mercedes es constante, también en la banda de sonido, incluso si, como apuntábamos su marca no es apenas mostrada.

En definitiva, los recursos formales son muy diversos pero encuentran cohesión en la edición, también en la repetición de personajes, motivos y escenarios, así como en el tratamiento de la iluminación y de otros aspectos de la puesta en escena, en definitiva.

El análisis de la edición del clip nos lleva a la conclusión, en primer lugar, de que la percepción de ritmo es rápida, al sumar a los recursos anteriores la brevísima duración de sus planos. En definitiva, aplica una concepción del vídeo musical muy convencional en cuanto a la edición: aun sin tratarse de un metavideoclip, es una pieza que mantiene pautas y recursos habituales en el formato. Afirma Selva (2014: 489) que es frecuente que "el videoclip busque una sensación de movimiento a todos los niveles, lo cual puede lograrse con movimiento dentro del cuadro, pero resulta más frecuente que se traduzca en un montaje ágil y rápido".

La velocidad de los planos es normal, salvo un par de tomas en ralentí coincidentes con momentos de alucinación del personaje (además, reforzados con una desaceleración también de la banda de sonido), mientras que en los planos con el automóvil corriendo por las calles intuimos que se ha acelerado su velocidad. El uso de velocidades de obturación lentas para filmar exteriores nocturnos explica por qué las luces del vehículo y de los edificios se convierten en ráfagas de luz que potencian la impresión de rapidez.

Las transiciones son al corte, como forma de cambio de planos capaz de aportar más contundencia y ritmo en cada cambio de plano. En algunas ocasiones las transiciones entre planos proceden de los propios planos filmados, como barridos de cámara que no permiten identificar motivos salvo luces en movimiento, pero que se intercalan entre los planos. 
La atención a la postproducción revela el cuidado del etalonaje (retoque de colorimetría), que aporta unidad entre los planos, además de un uso evidente de efectos VFX en los planos en los que el intérprete parece volar hasta el escenario de un local, así como en los efectos lumínicos dinámicos que resultan de la alucinación del personaje, o en la introducción del texto con el nombre de la canción.

Siguiendo tendencias más actuales, aparecen textos extradiegéticos al comienzo (artista y título de la canción) y al final, con créditos al director, al intérprete (esta vez con su nombre real), a la actriz que representa a la cantante de rasgos asiáticos y a la productora. Aparte de reivindicar la autoría, los títulos de crédito en el videoclip lo acercan como formato al cortometraje, como pieza audiovisual breve con una narrativa completa, con apertura y cierre.

Aunque no es propiamente un metavideoclip, la propuesta de The Weeknd es tan tópica en sus aspectos formales que podría reivindicarse como videoclip modélico. Puede argumentarse que esta referencia a recursos formales característicos de los videoclips de grupos New Wave de los ochenta responde a la voluntad de aunar una canción de estilo retro con un videoclip que pretende ser también retro aposta. El single, como hemos apuntado, alcanzó el primer puesto en Billboard y acumula millones de reproducciones en YouTube, lo que lleva a pensar que el espectador de videoclips no castiga la repetición de fórmulas ni la ausencia de originalidad en el formato.

Apuntemos con respecto a la integración de la marca y del vehículo desde una perspectiva formal, en primer lugar, que, en cuanto a tipos de planos, se alternan planos detalles (marca, faros, indicadores de velocidad, detalles del rostro del personaje mientras conduce, detalles de las manos sobre el volante) con otros planos enteros y planos generales que recogen al vehículo en desplazamiento, con una gran variedad de angulaciones. De esta forma, se cuida la presentación exterior del automóvil y se atiende igualmente a los detalles que hacen destacar a aquel, así como se introducen las brevísimas inserciones de la marca Mercedes. Prácticamente todos los planos interiores o exteriores del automóvil tienen algún tipo de movimiento (travelling, cámara en mano, zoom e incluso un zoom digital), lo que incrementa la impresión de velocidad del vehículo.

El análisis de la edición del vídeo plano a plano nos permite llegar a resultados interesantes: los planos exteriores del automóvil o filmados desde el interior ocupan un minuto, 19 segundos y seis frames (1.980 frames en total, en sistema PAL). Esto supone exactamente un $30 \%$ de la duración completa del videoclip. Esta precisión de la duración de los planos del vehículo invita a pensar que se ha pactado hasta el menor detalle la presencia del producto y de la marca en el clip. En total, se editan 73 planos mostrando el automóvil o su interior. Considerando la duración del total de estos 73 planos del vehículo, la media de cada plano sería de un segundo y dos frames. Los escasos planos (apenas cuatro) en los que es mostrada con relativa nitidez la insignia del vehículo son de una duración tan breve (apenas nueve frames), que disimulan bastante bien la naturaleza comercial del vídeo. Insistimos en la idea de que la velocidad de edición es tremenda, aspecto que contribuye a transmitir de nuevo la idea de velocidad asociada al videoclip, pero también al vehículo.

Este protagonismo del producto se potencia por la inserción del sonido ambiente procedente del coche. Además, el título del videoclip (Blinding Lights) aparece sobre un plano frontal del vehículo, donde se aprecia el logotipo de Mercedes. En este plano las luces de los faros se intensifican hasta crear entre ambos un efecto parecido al de un rayo a través de 
efectos visuales (VFX). El rayo creado digitalmente, como figura que podemos asociar a la idea de velocidad, se suma así a la impresión de ritmo y rapidez que transmite el conjunto del videoclip, en general, y del automóvil, en particular.

\subsection{Análisis de la puesta en escena}

Tabla 4. Análisis de la puesta en escena

\begin{tabular}{|l|l|}
\hline Composición & Simétrica \\
\hline Escenografía & Natural \\
\hline Iluminación & Realista/dramática \\
\hline Caracterización & Realista \\
\hline Actuación & Excesiva, exagerada. \\
\hline
\end{tabular}

Fuente: elaboración propia

El análisis de la puesta en escena muestra el seguimiento de tendencias habituales en el vídeo musical. En primer lugar, destaca la composición simétrica de los planos: los motivos principales tienden a situarse en el centro del encuadre, evitando composiciones más arriesgadas. La convencionalidad de la planificación, el sentido de las angulaciones de cámara y la adecuación a lenguajes funcionales y coherentes con la gramática audiovisual televisiva y cinematográfica se refuerza con la composición de los planos en los que se centra el motivo principal.

La atención a las escenografías, en segundo lugar, muestra una preferencia por la representación de espacios realistas, ya sean naturales o recreados en plató. La célebre calle Fremont Street en Las Vegas y su insólita iluminación a través de pantallas y carteles de led luminosos supone un espacio real, una localización natural, si bien conforma un escenario que no lo parece dada la artificialidad que recrea. Los exteriores urbanos nocturnos también responden a la necesidad de crear una impresión de realismo, sin que se advierta demasiada intervención sobre los mismos.

De forma coherente con estas opciones formales, la iluminación pretende ser realista, si bien el protagonismo de la misma es tal que consideramos que se usa de una forma dramática, con planos que recogen únicamente motivos luminosos, junto con otros filmados con una baja velocidad de obturación para convertir las luces en ráfagas de color en movimiento. Responde así al título de la canción, Blinding Lights ("luces cegadoras"), con una función activa en la puesta en escena que remite a la letra del tema.

Pese a la voluntad realista de los componentes de la puesta en escena, la actuación del intérprete no pretende serla y resulta excesiva, exagerada, al llevar al límite su expresión gestual. Esta interpretación exagerada encuentra su sentido en la letra del tema musical, incrementando la expresión de las emociones del intérprete. Desde el punto de vista del relato, podría justificarse por el estado de embriaguez y alucinación que envuelve al personaje.

Podríamos concluir que, en líneas generales, el videoclip de Blinding Lights no ha destacado por la aplicación de prácticas excesivamente rupturistas en la puesta en escena, de forma paralela al escaso riesgo asumido en la articulación 
formal del vídeo en general. A pesar de la espectacularidad de algunos planos, de las tomas de acción del vehículo y de la introducción de algunos planos con VFX, la puesta en escena basada en escenarios naturales, el limitado número de personajes y la propia filmación, como apuntamos, en apenas cuatro noches, nos llevan a pensar que estamos ante una producción de un presupuesto más bien contenido pero con resultados efectistas.

Los aspectos relativos a la puesta en escena en cuanto a la integración de la marca y del producto subrayan las cuestiones que ya hemos comentado. Los planos con el vehículo como motivo principal o como espacio en el que el personaje actúa tienden a ser simétricos, se muestra en un escenario natural básicamente realista y la iluminación participa tanto de los momentos realistas como de los más expresivos y dramáticos. Destaquemos como detalle particular con respecto a la iluminación que, desde el primer momento en que aparece el modelo de Mercedes que conduce The Weeknd, se destaca con claridad e intensidad la iluminación roja de sus faros, subrayando el sentido de la letra de la canción y sus "luces cegadoras". Más adelante aparecerán planos exteriores iluminados por luces rojas muy direccionales: hemos entendido a través de los planos anteriores que dichos planos se corresponden con los espacios por los que circula el vehículo, sin que importe que éste no sea mostrado en el plano.

\section{Discusión}

Partíamos de la hipótesis de que el vídeo musical del año 2020 para MTV hacía un uso de un lenguaje formal convencional dentro de las pautas del formato, afirmación que creemos demostrada a través del análisis textual aplicado. El vídeo musical de vanguardia abierto a la máxima experimentación y objeto de la aplicación de técnicas creativas y explorativas sigue vigente y ofrece muchas y variadas muestras cada año. Sin embargo, el clip premiado en certámenes abiertos a propuestas comerciales, como los MTV VMA es el vídeo que no arriesga y que responde al mantenimiento de pautas y fórmulas conocidas y frecuentes, al punto de ser objeto de parodias.

No hemos partido de la comparación con otros referentes que pudieran identificar pautas formales en el formato, si bien, encontramos aquí puntos en común en cuanto a aspectos formales con las pautas presentes en el vídeo paródico de YouTube de Tom Scott (2018): inicio en cámara lenta con un personaje en un espacio descontextualizado, circularidad del discurso narrativo, edición de planos de brevísima duración sin continuidad entre ellos, aceleración de algunos planos, introducción de marcas comerciales, presencia del sonido ambiente para dotar de realismo la representación de acciones, etc. A pesar de las muchas excepciones que pudieran encontrarse en todo el universo de vídeos musicales premiados por la MTV, podemos concluir que Blinding Lights de The Weeknd hace un uso de sus recursos formales siguiendo pautas formales y convenciones discursivas y narrativas.

Podríamos argumentar que el vídeo analizado es intencionadamente convencional, por cuanto en el plano musical homenajea la música techno-pop de los años 80 , y de forma más concreta Take on me de A-ha, y de forma paralela pretende hacer un discurso basado en la nostalgia, un videoclip retro donde todos sus recursos remiten a los patrones que podrían identificarse como propios del vídeo musical. Comentábamos antes que, aunque no se trata de un metavideoclip, la convencionalidad en el seguimiento de un lenguaje prácticamente normalizado del vídeo musical lo convertía en un modelo representativo de todo el formato. 
El vídeo del año para MTV remite así al formato modélico programado por la cadena en los años 80, con lo que, de alguna forma, la cadena recurre a la nostalgia para premiarse a sí misma, o a la identidad con la que se promocionó en sus orígenes. Esta misma voluntad de auto-homenaje puede apreciarse en otros dos vídeos nominados a la categoría de Vídeo del año MTVVMA 2020: The Man de Taylor Swift, dirigido por la misma cantante, y Life is Good de Future ft. Drake, dirigido por Director X, que sí son metavideoclips al presentarse el rodaje de un videoclip en la propia pieza.

Creemos además que Blinding Lights es representativo de la producción de vídeos musicales en el contexto contemporáneo por su evidente finalidad comercial, no ya de la canción, sino de la marca automovilística que lo produce. La asociación de Mercedes-Benz con un intérprete y un productor musical de prestigio (The Weeknd y Max Martin) para la producción de contenidos en torno a la marca, como acción de branded content, ha terminado por revelarse como una estrategia eficaz en la que los agentes comerciales y los culturales han retroalimentado su prestigio mutuamente para conseguir unos resultados satisfactorios, en impacto y en reconocimiento público: el premio MTV a Vídeo del año es prueba de ello.

Creemos que resulta muy significativo que el videoclip considerado vídeo del año por la audiencia de MTV y por la cadena de televisión forme parte de la campaña de branded content de una marca. La industria discográfica entró en una profunda crisis con el inicio del siglo, fruto del cambio en los hábitos de ocio de la audiencia, de las nuevas formas de consumo de contenidos musicales y de la piratería a través de Internet, crisis de la que empezó a recuperarse a partir de 2014 tras tocar fondo en 2013. Las discográficas, como responsables de la producción del formato, tuvieron dificultades en la financiación del vídeo musical y agudizaron el ingenio a la hora de lograr acuerdos comerciales con marcas para mantener la producción de clips de alto presupuesto. El recurso a estrategias como las de branded content y product placement son, por tanto, consecuencias de la crisis de la que aún intenta reponerse la industria discográfica en la actualidad.

La paradoja es que la abierta relación de The Weeknd con la marca y con sus objetivos comerciales no mella en la aceptación del vídeo musical; la audiencia no ha rechazado esta vinculación del producto cultural con la marca comercial. Asimismo, como hemos apuntado, la repetición de pautas y el uso de un lenguaje tópico y convencional en la creación del vídeo musical también ha contado con el aplauso del público.

La hibridación del vídeo musical con otros formatos da un paso más con el videoclip diseñado como producción comercial dentro de una estrategia de branded content. La clave para que el espectador no lo perciba como un anuncio de televisión de mayor duración y no rechace su abierta comercialidad estaría, como hace Blinding Lights, en proponer un contenido de calidad, atractivo, que aporta valor por sí mismo: en este caso, se suman una canción pegadiza producida por el célebre productor Max Martin e interpretada por una de las estrellas del momento, con un relato que genera intriga y tensión y una articulación formal con una realización ágil y un enorme ritmo en la edición, capaces de seducir a la audiencia. Apuntemos además que la marca y el producto se integran con naturalidad en el relato y pese a su enorme protagonismo (presentes durante un $30 \%$ de la duración del videoclip), no llega a percibirse la subordinación de la pieza a un objetivo comercial. 
Concluimos, por tanto, que Blinding Lights es un videoclip representativo en el desarrollo del lenguaje del vídeo musical, además de ser consecuencia de un contexto de producción en el que la financiación se convierte en un problema, problema resuelto con la asociación con empresas de sectores no directamente culturales a través de estrategias de branded content. Apuntemos, con respecto al contexto en que se distribuye el vídeo, que YouTube y las redes sociales facilitan la distribución de producciones creadas como contenido de marca, por cuanto no cuentan con las limitaciones que los canales de televisión lineal pudieran introducir al evitar la programación de contenidos comerciales que escapan a su control. La paradoja está, una vez más, en que es un canal de televisión lineal, MTV y su audiencia, quien premia un vídeo concebido como contenido de marca.

Habida cuenta de las conclusiones a las que llega este trabajo, proponemos para futuras investigaciones ampliar el análisis de los vídeos premiados por MTV desde los criterios formales que aquí hemos considerado y que pasan por un análisis textual del vídeo musical, así como otros clips producidos dentro de estrategias de branded content. Cabría preguntarse igualmente, y es una cuestión a la que emplazamos para una futura investigación, si los premios MTV premian a los mejores videoclips o a las canciones más populares del año, con independencia del vídeo musical, hecho que cuestionaría la propia naturaleza de los galardones.

\section{Referencias bibliográficas}

Billboard (12 de febrero de 2019). The Weeknd Partners With Mercedes-Benz in New Electric SUV Ad Pitch. Billboard. https://tinyurl.com/y2aa48x6

Blanco, S. (2020). Behind the Scenes as Mercedes-AMG GT Stars in The Weeknd's Video. Car and Driver. https://tinyurl. com/yabvh883

Bonde Korsgaard, M. (2017). Music Video After MTV: Audiovisual Studies, New Media, and Popular Music. Abingdon: Routledge.

Casetti, F. y Di Chio, F. (1991). Cómo analizar un film. Barcelona: Paidós.

Del Pino-Romero, C. y Castelló-Martínez, A. (2015). La comunicación publicitaria se pone de moda: branded content y fashion films. Revista Mediterránea de Comunicación, 6(1), 105-128. https://doi.org/10.14198/MEDCOM2015.6.1.07

Costa-Sánchez, C. (2015). El cambio que viene. Audiovisual branded content. Telos, 99, 84-93. https://tinyurl. com/5xcahq3y

Gow, J. (1996). Reconsidering Gender Rols on MTV: Depictions in the Most Popular Music Videos Early 1990s. Communication Reports, 9(2), 151-161. http://dx.doi.org/10.1080/08934219609367647

Guarinos-Galán, V. y Sedeño-Valdellós, A.M. (2020). El videoclip social. Análisis de su narrativa y estética. Methaodos. Revista de ciencias sociales, 8(1), 120-129. http://dx.doi.org/10.17502/m.rcs.v8i1.329

Horrigan, D. (2009). Branded content: a new model for driving tourism via film and branding strategies. Tourismos: An International Multidisciplinary Journal of Tourism, 4(3), 51-65. https://mpra.ub.uni-muenchen.de/25419/ 
Illescas-Martínez, J.E. (2017). El contenido del videoclip dominante como reproductor cultural e ideológico. Revista Mediterránea de Comunicación, 8(2), 85-104. https://doi.org/10.14198/MEDCOM2017.8.2.6

Imvdb.com (2020). Anton Tammi. Videography. Imvdb.com. https://imvdb.com/n/anton-tammi

López Noguero, F. (2002). El análisis de contenido como método de investigación. XXI Revista de Educación, 4, 167-179. https://tinyurl.com/y9nsh8te

Pérez-Rufí, J.P. (2011). Recursos formales en el videoclip actual. La opción mainstream. Razón y palabra, 75. https:// tinyurl.com/yyv7gyz6

Pérez-Rufí, J.P., Navarrete-Cardero, J.L. y Gómez-Pérez, FJ. (2014). El product placement en el videoclip: análisis de contenido del emplazamiento de marca en los vídeos musicales preferidos por los usuarios de YouTube. Doxa Comunicación, 18, 83-104. https://doi.org/10.31921/doxacom.n18a4

Pérez-Rufí, J.P. y Jódar-Marín, J.A. (2019). El análisis textual del videoclip: una propuesta metodológica. En F. Sierra Caballero y J. Alberich Pascual (Coords.). Epistemología de la comunicación y cultura digital: Retos emergentes (pp. 297-310). Granada: Universidad de Granada.

Rodríguez-López, J. (2014). Diseño de un modelo crítico-estilístico para el análisis de la producción videográfica musical de Andy Warhol como industria cultural. (Tesis doctoral). Universidad de Huelva, Huelva.

Rodríguez-López, J. (2016). El vídeo musical como formato postmoderno: La ruptura de los códigos audiovisuales a través del clip. Doxa Comunicación, 21, 13-30. https://doi.org/10.31921/doxacom.n22a1

Rodríguez-López, J. y Pérez-Rufí, J.P. (2017). El videoclip como spot. Presencia y evolución del Product Placement en el vídeo musical. Pensar la publicidad, 11, 69-82. https://doi.org/10.5209/PEPU.56394

Roig, A. y San Cornelio, G. (2015). Prácticas de cocreación en vídeos musicales: el caso de Evolution of Get Lucky. Anàlisi. Quaderns de Comunicació i Cultura, 51, 49-63. http://dx.doi.org/10.7238/a.v0i51.2321

Sánchez-Olmos, C. (2018). Formatos y sectores en el branded content musical:Videoclip y moda, pop stars de la musicidad. Revista Mediterránea de Comunicación, 9(2), 305-319. https://www.doi.org/10.14198/MEDCOM2018.9.2.5

Sánchez-Olmos, C. , Segarra Saavedra, J. y Hidalgo Marí, T. (2019). Brand Placement en los videoclips del Billboard Hot 100: ¿integración o imposición de marcas? Trípodos, 44, 63-81. https://doi.org/10.51698/tripodos.2019.44p63-81

Scott, T. (15 de octubre de 2018). If Educational Videos Were Filmed Like Music Videos. [Archivo de vídeo] YouTube. https://youtu.be/G025oxyWv0E

Sedeño-Valdellós, A.M. (2002). Lenguaje del videoclip. Málaga: Servicio de Publicaciones de la Universidad de Málaga.

Sedeño-Valdellós, A.M. y Schubert, H. (2020). Product placement en el videoclip musical mainstream: análisis de los casos más visualizados en YouTube de 2015 a 2019. Estudios sobre el Mensaje Periodístico, 26(4), 1599-1610. http://dx.doi. org/10.5209/esmp.69212

Selva-Ruiz, D. (2010). La difusión global del videoclip a través de MTV: ¿One Planet, One Music? En B. León Anguiano (Coord.). Informativos para la televisión del espectáculo (pp. 125-134). Zamora: Comunicación Social. 
Selva-Ruiz, D. (2014). El videoclip. Comunicación comercial en la industria musical. Sevilla: Ediciones Alfar.

Tannenbaum y Marks (2011). I Want My MTV: The Uncensored Story of the Music Video Revolution. Boston: Dutton Penguin.

Tarín Cañadas, M. (2012). La narrativa en el videoclip Knives Out, de Michel Gondry. Icono 14, 10 (2), 148-167. http:// dx.doi.org/10.7195/ri14.v10i2.482

Vernallis, C. (2013). Unruly Media. YouTube, Music Video, and the New Digital Cinema. Oxford: Oxford University Press.

Vernallis, C., Rogers, H. y Perrott, L. (eds). (2019). Transmedia Directors. Artistry, Industry and New Audiovisual Aesthetic. Londres: Bloomsbury Academic.

Viñuela Suárez, E. (2008). La autoría en el vídeo musical: signo de identidad y estrategia comercial. Revista Garoza, 8, 235-247. https://tinyurl.com/y3voc72y 
